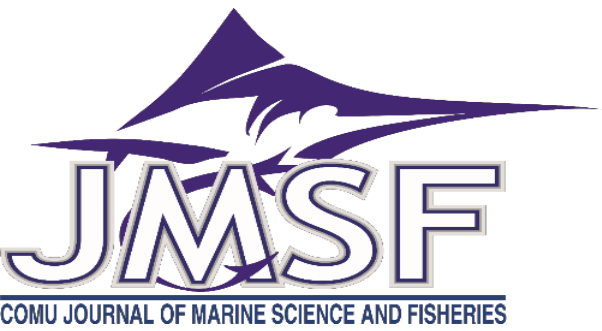

\title{
Effect of Liquid Seaweed Extract on Growth and Biochemical Composition of Treptacantha barbata (Phaeophyceae)
}

\author{
Merve Künili ${ }^{1}$, İlknur Ak*2 \\ 1* Çanakkale Onsekiz Mart Üniversitesi, Lisansüstü Eğitim Enstitüsü, Su Ürünleri Yetiştiriciliği A.B.D., Terzioğlu Kampüsü, 17100, \\ Çanakkale/Türkiye \\ ${ }^{2}$ Çanakkale Onsekiz Mart Üniversitesi, Deniz Bilimleri ve Teknolojisi Fakültesi, Yetiştiricilik Bölümü, Terzioğlu Kampüsü, 17100, \\ Canakkale/Türkiye \\ Correspondent: ilknurak@comu.edu.tr \\ Received: 01.11.2020 Accepted: 18.11.2020 \\ İlknur Ak: Orcid 0000-0002-0233-0025
}

How to cite this article: Künili, M. \& Ak, İ.., (2020). Effect of liquid seaweed extract on growth and biochemical composition of Treptacantha barbata (Phaeophyceae). COMU J. Mar. Sci. Fish, 3(2): 111-119. DOI: 10.46384/jmsf.819485

\begin{abstract}
In this study, the effects of liquid extract from brown seaweed Colpomenia sinuosa on growth rate and biochemical composition of Treptacantha barbata were investigated. Liquid extract of $C$. sinuosa was used in two different concentrations $\left(1 \mathrm{ml} \mathrm{l}^{-1}\left(\mathrm{C}_{1}\right), 2 \mathrm{ml} \mathrm{l}^{-1}\left(\mathrm{C}_{2}\right)\right)$. Also, the Conway medium was used in the control group. The experiments were carried out for 35 days, and the highest growth rate and biomass yield was determined in $\mathrm{C} 1$ $(\mathrm{p}<0.05)$. The crude lipid of the groups varied from $1.18 \pm 0.03 \%$ ile $2.19 \pm 0.06 \%$. The highest crude protein content was found in the control and $\mathrm{C}_{1}$ groups. It was determined that there are statistically significant differences between the ash contents of all groups $(\mathrm{p}<0.05)$. Our results showed that saturated fatty acids (SFA) constituted more than half of all groups' fatty acid contents. Monounsaturated fatty acids (MUFA) content of groups varied between $23.51 \pm 0.23 \%$ and $25.36 \pm 0.22 \%$. In the study, it was determined that the $\mathrm{C}_{1}$ group had higher polyunsaturated fatty acid content compared to other experimental groups. As a result of the study, it was determined that $C$. sinuosa liquid extracts could be used as a nutrient medium in T. barbata cultivation.
\end{abstract}

Keywords: Treptacantha barbata, Colpomenia sinuosa, Cystoseira, Culture, Proximate Composition

\section{Sıvı Alg Özütünün Treptacantha barbata'nın (Phaeophyceae) Büyüme ve Biyokimyasal Kompozisyonuna Etkisi}

Özet: Bu çalışmada esmer alglerden Colpomenia sinuosa sıvı özütünün Treptacantha barbata'nın büyüme hızı ve biyokimyasal kompozisyonu üzerine etkileri araştırılmıştır. C. sinuosa sıvı özütü iki farklı konsantrasyonda (1 ml $\left.\mathrm{l}^{-1}\left(\mathrm{C}_{1}\right), 2 \mathrm{ml} \mathrm{l}^{-1}\left(\mathrm{C}_{2}\right)\right)$ kullanılmıştır. Ayrıca denemelerde Conway ortamının kullanıldığı bir kontrol grubu da oluşturulmuştur. 35 gün süren denemelerde en yüksek büyüme hızı ve biyomas verimi $\mathrm{C}_{1}$ grubunda saptanmıştır

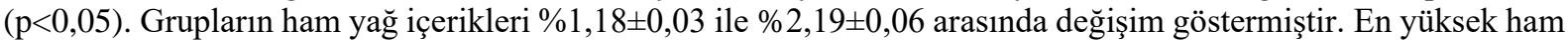
protein içeriği ise kontrol ve $\mathrm{C}_{1}$ gruplarında saptanmıştır. Tüm grupların kül içerikleri arasında istatistiksel açıdan önemli farklılıkların olduğu belirlenmiştir $(\mathrm{p}<0,05)$. Tüm grupların yağ asidi içeriklerinin yarısından fazlasını doymuş yağ asitlerinin (SFA) oluşturduğu gözlemlenmiştir. Deneme gruplarımızın tekli doymamış yağ asitleri

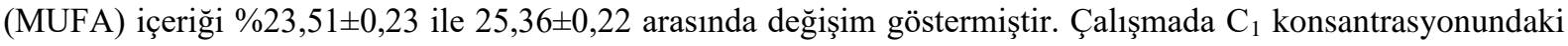
C. sinuosa sıvı özütü kullanılarak yetiştirilen T. barbata talluslarının diğer deneme gruplarına göre daha fazla çoklu doymamış yağ asidi içeriğine sahip olduğu belirlenmiştir. Çalışma sonucunda T. barbata yetiştiriciliğinde C. sinuosa sıvı özütlerinin besin tuzu olarak kullanılabileceği saptanmıştır.

Anahtar Kelimeler: Treptacantha barbata, Colpomenia sinuosa, Cystoseira, Yetiştiricilik, Besin Kompozisyonu 


\section{Giriş}

Makro algler birçok canlı için üreme, barınma ve beslenme alanlarını oluşturmalarının yanı sıra 12 bin yıldan fazla bir süredir insanoğlu tarafından başta gıda olmak üzere tarım, sanayi ve ilaç gibi birçok alanda kullanılmaktadır (Ak, 2015). Ayrıca, makro algler mineral, protein, yağ asitleri, vitaminler, ikincil metabolitler ve biyoaktif maddeler bakımından zengin olmaları nedeniyle de fonksiyonel gida olarak değerlendirilmektedir (Ak ve Türker, 2018; Ak, 2015). Özellikle yaklaşık son 40 yıldır gelişen teknoloji ile makro alglerin gıda, tarım kozmetik ve ilaç alanlarında kullanım talebinin artmasıyla birlikte üretimi de hiz kazanmıştır. 2018 y1lı FAO verilerine göre yetiştiriciliği yapılan makro alg miktarı son 20 yılda \%346 kat artış göstererek 9,296 milyon tondan 32,199 milyon tona ulaşmıştır (FAO, 2020). Bu üretimin \%53,54'ünü kırmızı algler, \%46,40'ını esmer algler ve $\% 0,06$ 'sını ise yeşil algler oluşturmaktadır (FAO, 2020). Makro alglerin kullanım alanlarının yaygınlaşması ile önümüzdeki yıllarda da yetiştiricilik miktarının artacağı öngörülmektedir (Borges, Araujo, Azevedo ve Pinto, 2020). Hem artan talebi karşılamak hem de üretim maliyetini azaltmaya yönelik yapılan araştırmalar da son yıllarda hız kazanmıştır. Bu çalışmalarda 1şık, sıcaklık, tuzluluk, $\mathrm{pH}$, besin tuzları gibi faktörlerin algin büyüme hızı ve/veya biyokimyasal içerikleri üzerine etkileri incelenmiştir (Baghdadli, Tremblin, ve Ducher, 1994; Bastos, 2019; Bollen, Pilditch, Battershill ve Bischof, 2016; Floreto, Hirata, Ando ve Yamasaki, 1993; Gong, Liu ve Zou, 2020). Ancak alg üretiminde ortam koşullarının yanı sıra kullanılan besin tuzları alglerin büyüme ve biyokimyasal içeriklerine etki eden en önemli faktörlerden biridir. Ortamda bulunan besin tuzu türevlerine ve miktarına göre alglerin biyokimyasal içerikleri de farklılık göstermektedir (Ak, Öztaşkent, Özüdoğru ve Göksan, 2015; Cirik, Şen ve Ak, 2010; Toth, Harrysson, Wahlström, Olsson, Oerbekke, Steinhagen, Kinnby, White, Albers, Edlund, Undeland ve Pavia, 2020). Alg yetiştiriciliğinde genellikle maliyeti yüksek olan inorganik besin tuzları kullanılmaktadır. Hem organik sıvı bitki özütlerinin alglerin büyümesi ve biyokimyasal kompozisyonlarına etkisi üzerine (Ak, Çetin, Cirik ve Göksan, 2011; Pacheco-Ruíz, Zertuche-González, Arroyo-Ortega ve Valenzuela-Espinoza, 2004; Raoof, Kaushik ve Prasanna, 2006; Werlinger, Mansilla, Villarroel ve Palacios, 2009) hem de siv1 alg özütlerinin mikro ya da makro alg yetiştiriciliğinde kullanımı ile ilgili çok az sayıda araştırma mevcuttur (Abdel-Kareem, Mohy El.Din ve Ibrahim, 2020; Kaladharan, Gireesh ve Smitha, 2002; Künili ve Ak, 2020; Loureiro, Reis ve Critchley, 2010; RobertsonAndersson, Leitao, Bolton, Anderson, Njobeni ve Ruck, 2006). Bu çalışmalarda Sargassum, Ecklonia, Ascophyllum, Ulva ve Pterocladia cinslerinin siv1 özütleri alg yetiştiriciliğinde kullanılmış olup, sıvı özütlerin kullanıldığı grupların kontrol gruplarına yakın veya daha yüksek büyüme hızlarına sahip olduğu araştırmacılar tarafından bildirilmiştir.

Ulva sp., Enteromorpha sp., Sargassum sp., Codium sp. gibi algler besin tuzlarının bol bulunduğu bölgelerde zaman zaman aşırı çoğalarak çevre felaketlerine de yol açmaktadır. Güney Çin, Sargas ve Manş denizlerine kıyısı olan ülkeler aşırı alg çoğalmalarından olumsuz etkilenmektedir (CasasBeltrán, Gallaher, Hernandez Yac, Febles Moreno, Voglesonger, Leal-Bautista ve Lenczewski, 2020; Jones, Quillien, Fabvre, Grall, Schaal ve Le Bris, 2020). Ülkemizde ise İzmir Körfezi'nde "green tide" olarak adlandırılan yeşil alglerden Ulva türlerinin yol açtığı aşırı makro alg çoğalmasının görülme sıklığı son yıllarda artış göstermektedir (A. Ajansı, 2018; D. H. Ajansı, 2020). Bu aşırı çoğalmalar yarattıkları çevre sorunlarının yanı sıra ekonomik anlamda da ciddi kayıplara neden olmaktadır. Ayrıca, sahil şeridinde biriken alg biyomasları da değerlendirilmeden bertaraf edilmektedir. Oysa ki, bu biyomasın farklı şekillerde değerlendirilmesi bir nebze de olsa ekonomik kaybı azaltabilir. Azot, fosfat ve pigment içeriklerinin yüksek olmasının yanı sıra oksin, giberellin, sitokin ve absisik asit gibi bazı biyoaktif madde içerikleri nedeniyle dünya genelinde birçok ülke sahil kıyılarında biriken makro algleri gübre olarak değerlendirmekte ve yaygın şekilde kullanılmaktadır (Ak, 2015). Ülkemizde ise makro alglerden gübre üretimine yönelik bir sektör olmamasına karşın makro alg kökenli gübre kullanımının yaygınlaştığı çeşitli araştırmalarda rapor edilmektedir (Ak, 2015; Engin, Yağmur, Cirik, Okur, Eşiyok ve Gökpınar, 2019; Eşiyok ve Bozokalfa, 2007; Turan ve Köse, 2004). Ancak, ülkemizde alg yetiştiriciliğinde makro alglerin kullanımına yönelik yapılmış bir çalışma bulunmamaktadir.

Çalışma kapsamında Çanakkale sahil şeridinde biriken esmer alglerden Colpomenia sinuosa'dan elde edilen sıvı özütler önemli bir aljinat kaynağı olan Treptacantha barbata yetiştiriciliğinde kullanılmıştır. Deneme gruplarının büyüme hızları, biyomas verimleri ve biyokimyasal kompozisyonlarında meydana gelen değişimler belirlenmiştir.

\section{Materyal ve Yöntem}

\section{Materyal}

Çalışmada sıvı özütü elde edilen Colpomenia sinuosa (Mertens ex Roth) Derbès \& Solier 1851 ve Treptacantha barbata (Stackhouse) Orellana \& Sansón Çanakkale Boğazı Kepez mevkiinden $\left(40^{\circ}\right.$ 6'42.71"N, 26²4'6.60"E) toplanmıştır. Algler üzerindeki epifitik organizmalar ayıklanmış ve sonrasında steril deniz suyu ile yıkanmıştır. Yetiştiricilik denemelerinde kullanılacak olan $T$. barbata tallusları 15 gün boyunca Conway ortamı (Tompkins, Deville, Day ve Turner, 1995) kullanılarak ortama adapte olmaları sağlanmıştır. Conway ortami; $\mathrm{KNO}_{3}, 100 \mathrm{~g} / \mathrm{m}^{3} ; \mathrm{Na}_{2} \mathrm{HPO}_{4}, 20 \mathrm{~g} / \mathrm{m}^{3}$ ve $1 \mathrm{ml}$ iz element solüsyonu $\left(\mathrm{FeCl}_{3} \cdot 6 \mathrm{H}_{2} 0,1,3 \mathrm{~g} / \mathrm{m}^{3}\right.$; 
$\mathrm{Na}_{2} \mathrm{H}_{2}$ EDTA. $2 \mathrm{H}_{2} \mathrm{O}, 45 \mathrm{~g} / \mathrm{m}^{3} ; \mathrm{H}_{3} \mathrm{BO}_{3}, 33,4 \mathrm{~g} / \mathrm{m}^{3}$; $\mathrm{CuSO}_{4} .5 \mathrm{H}_{2} \mathrm{O}, \quad 4,0 \mathrm{~g} / \mathrm{m}^{3} ; \mathrm{CoCl}_{2} .6 \mathrm{H}_{2} \mathrm{O}, \quad 4,0 \mathrm{~g} / \mathrm{m}^{3}$; $\mathrm{MnCl}_{2} .4 \mathrm{H}_{2} \mathrm{O}, 0,36 \mathrm{~g} / \mathrm{m}^{3} ;\left(\mathrm{NH}_{4}\right) 6 \mathrm{Mo}_{7} \mathrm{O}_{24 .} 4 \mathrm{H}_{2} \mathrm{O}, 1,8$ $\left.\mathrm{g} / \mathrm{m}^{3} ; \mathrm{ZnCl}_{2}, 4.2 \mathrm{~g} / \mathrm{m}^{3}\right)$

\section{Sıvı özütün yapımı ve özütün mineral madde içeriği}

C. sinuosa talluslarından sivı özüt eldesi (Sivasankari, Venkatesalu, Anantharaj ve Chandrasekaran, 2006)'e göre yapılmıştır. Elde edilen makro alg özütü $0-4^{\circ} \mathrm{C}$ 'de denemeler süresince saklanmıştır. Deneme grupları oluşturulmadan önce hazırlanan sıvı özütün mineral madde içeriği ICP-AES (Varian Liberty AX Sıralı ICP-AES) kullanılarak saptanmıştır. Sıvı C. sinuosa özütünün mineral madde içeriği, İskandinav Gıda Analizi Komitesi'nin yöntemine (No: 186) (NMKL, 2007) göre belirlenmiştir. Tüm analizler üç paralel ve üç tekrarlı olarak gerçekleştirilmiştir. Analiz edilen bileşikler ve elementler sirasiyla amonyum $\left(\mathrm{NH}_{4}^{+}\right)$, nitrit $\left(\mathrm{NO}_{2}^{-}\right)$, nitrat $\left(\mathrm{NO}_{3}{ }^{-}\right)$, fosfat $\left(\mathrm{PO}_{4}^{-3}\right)$, sülfat $\left(\mathrm{SO}_{4}^{-2}\right)$, magnezyum $\left(\mathrm{Mg}^{2+}\right)$, kalsiyum $\left(\mathrm{Ca}^{2+}\right)$, demir $\left(\mathrm{Fe}^{2+}\right)$ ve bakırdır $\left(\mathrm{Cu}^{2+}\right)$. Elde edilen sonuçlar standartlarla (VH6 Lab Tek Elementli Atomik Absorpsiyon CRM) karşılaştırılarak g/l olarak ifade edilmiştir (Tablo 1).

\section{Yetiştiricilik denemeleri, büyüme hızı ve biyomas verimi hesaplamalart}

Deneme gruplarında kullanılan sıvı özüt miktarları Tablo 1'de gösterilmiştir. $\mathrm{C}_{1}$ için $1 \mathrm{ml} / 1, \mathrm{C}_{2}$ için $2 \mathrm{ml} / 1$ olacak şekilde ayarlanmıştır. Conway (Tompkins ve diğ., 1995) ortamı kontrol grubunda kullanılmıştır. $T$. barbata talluslarının stok yoğunluğu $15 \mathrm{~g} / 1$ olacak şekilde ayarlanmıştır. Denemeler 3 l'lik cam kaplarda gerçekleştirilmiş olup denemeler süresince beş günde bir biyomas başlangıç yoğunluğuna gelecek şekilde hasat edilmiştir. Denemeler 35 gün boyunca sürdürülmüştür. Sıvı alg özütleri denemeler süresince her gün kültür kaplarına ilave edilmiştir. Işık yoğunluğu $100 \mu \mathrm{mol}$ foton $/ \mathrm{m}^{2} \mathrm{~s}$ olacak şekilde 1şıkölçer (LI-250) yardımı ile ayarlanmıştır. Tallusların kültür kaplarındaki homojenizasyonu için tüm gruplarda havalandırma kullanılmıştır. Denemeler süresince grupların $\mathrm{pH}$ ve sıcaklık ölçümleri günde iki defa $1{ }^{\circ} \mathrm{C}$ duyarlılıktaki termometre ve $\mathrm{pH}$ metre (Hanna, HI8314) yardımıyla yapılmıştır. Deneme gruplarının büyüme hızları ve biyomas verimleri Troell, Halling, Nilsson, Buschmann, Kautsky ve Kautsky (1997) ve Smith ve Walker (1980)' a hesaplanmıştır.

Tablo 1. Sıvı gübrenin ve deneme gruplarının besin tuzu içerikleri.

\begin{tabular}{cccc}
\hline & Sıvı gübre $(\mathbf{g} / \mathbf{l})$ & $\mathbf{C}_{\mathbf{1}}\left(\mathbf{x} \mathbf{1 0}^{-\mathbf{3}} \mathbf{g} / \mathbf{l} / \mathbf{g u ̈ n}\right)$ & $\mathbf{C}_{2}\left(\mathbf{x} 10^{-3} \mathbf{g} / \mathbf{l} / \mathbf{g u ̈ n}\right)$ \\
\hline $\mathrm{NO}_{3}{ }^{-}$ & 25 & 25 & 50 \\
$\mathrm{NO}_{2}{ }^{-}$ & 15 & 15 & 30 \\
$\mathrm{NH}_{4}{ }^{+}$ & 0,10 & 0,10 & 0,20 \\
$\mathrm{PO}_{4}^{-3}$ & 2,80 & 2,80 & 5,60 \\
$\mathrm{SO}_{4}^{-2}$ & 23,20 & 23,20 & 46,40 \\
$\mathrm{Ca}^{+}$ & 401,60 & 401,60 & 803,20 \\
$\mathrm{Mg}^{+2}$ & 53,5 & 53,50 & 107,00 \\
$\mathrm{Cu}^{+2}$ & 1,2 & 1,20 & 2,40 \\
$\mathrm{Fe}^{+2}$ & 0,3 & 0,30 & 0,60 \\
\hline
\end{tabular}

\section{Biyokimyasal içerikleri}

Hasat edilen talluslar $30{ }^{\circ} \mathrm{C}$ 'de 48 saat süresince kurutulmuş ve daha sonra ögütücü yardımıyla toz haline getirilmiştir. Hazırlanan örnekler ham protein, kül, nem, ham yağ ve yağ asidi analizlerinde kullanılmıştır. Ham protein tayini Kjeldahl yöntemine göre yapılmış olup organik azot içeriğinin hesaplanmasında faktör olarak 6,25 değeri kullanılmıştır (AOAC, 2000). Örneklerin nem ve kül içerikleri AOAC (2000) yöntemine göre belirlenmiştir. Ham yağ içeriği Folch, Lees ve Sloane Stanley (1957) yöntemi ile belirlenmiştir. Deneme gruplarının yağ asidi metil esterler (FAME) analizleri UIPAC (1979) yöntemine göre yapılmıştır. Thermo Finnigan Trace GC - MS DSQ, Xcalibur Ana Sayfa sürüm 1.4 SR1 yazılım olarak kullanılmıştır. $30 \mathrm{mX}$ 0.25 I.D. X $0.25 \mu \mathrm{m}$ film kalınlığında ZB-\%MS kolon ile FAME'ler ayrıştırılmıştır. Sıcaklık başlangıçta 60 ${ }^{\circ} \mathrm{C} 5$ dakika tutulmuş, $5{ }^{\circ} \mathrm{C} / \mathrm{dk}^{\prime}$ lık bir hızda $200{ }^{\circ} \mathrm{C}^{\prime} \mathrm{ye}$ 
yükseltilmiş ve 5 dakika $200{ }^{\circ} \mathrm{C}^{\prime}$ de tutulmuştur. Sicaklık, son olarak $5{ }^{\circ} \mathrm{C} / \mathrm{dk}^{\prime}$ lık bir hızda $260{ }^{\circ} \mathrm{C}^{\prime} \mathrm{ye}$ yükseltilmiş ve 20 dakika $260{ }^{\circ} \mathrm{C}^{\prime}$ de tutulmuştur. FAME'lerin pik tanımlaması, bilinen standartların (Supelco 37 Bileşen FAMEs Mix) tutma süreleri ve kütle spektrumlarının karşılaştırılmasıyla gerçekleştirilmiştir. GC-MS kromatogramları, yağ asitlerinin tanımlanması NIST ve Wiley kitaplıklarının karşılaştırılmasıyla yapılmıştır. Tüm analizler üç tekrarlı yapılmıştır. FAME'ler, makro alg örneklerinin toplam FAME'lerinin yüzdesi olarak sunulmuştur.

\section{İstatistiksel Analizler}

Denemeler sonucunda elde edilen veriler Tukey'in çoklu karşılaştırma testleri ile tek yönlü varyans analizi (ANOVA) ile analiz edilmiş olup farklar $p$ $\leq 0.05$ olduğunda anlamlı kabul edilmiştir. Tek yönlü varyans analizinden önce, tüm veriler, Özdamar (1997)'a göre PASW STATISTICS 19 yazılımı (IBM SPSS Inc., Chicago, IL) kullanılarak varyans homojenliği (Levene'nin eşit varyanslar için testi) ve normal dağılım (Anderson-Darling testi) açısından incelenmiştir.

\section{Bulgular ve Tartışma}

Bu çalışmalarda önemli bir aljinat kaynağı olan $T$. barbata'nın yetiştiriciliğinde $C$. sinuosa sıvı özütünün etkileri araştırılmıştır. Deneme gruplarının $\mathrm{pH}$ ve sicaklık değerleri sirasıyla $8,5 \pm 1,0$ ve $20,0 \pm 1,0{ }^{\circ} \mathrm{C}$ olarak ölçülmüştür. Cirik, Şen ve Ak (2010) tarafından her iki değerin de algin büyümesi için optimum değerler aralığında olduğu bildirilmiştir. Deneme gruplarının ortalama büyüme hızları ve biyomas verimleri Şekil 1'de gösterilmiştir. Çalışma sonucunda en yüksek büyüme hızı $\mathrm{C}_{1}$ grubunda $\% 20$ /gün olarak hesaplanmıştır $(\mathrm{p}<0,05) . \quad \mathrm{C}_{2}$ grubunun en düşük büyüme hızına sahip olduğu saptanmıştır. Gruplar arasında en yüksek biyomas verimi $\mathrm{C}_{1}$ grubunda saptanırken kontrol ve $\mathrm{C}_{2}$ grupları arasında istatistiksel yönden anlamlı bir farklılık bulunamamıştır ( $\mathrm{p}>0,05)$. Loureiro ve diğ. (2010) esmer alg Ascophyllum nodosum türünden elde edilen siv1 özütünün Kappaphycus alvarezii'nin büyüme hızı ve epifitik organizmaları üzerine etkilerini araştırmışlardır. Çalışma sonucunda bir saat boyunca 15-20 g/l konsantrasyonlardaki A. nodosum sıvı özütü ile banyo yaptırılan grupların daha hızlı büyüdüğünü ve daha az epifit problemi yaşadıklarını bildirmişlerdir. Kaladharan ve diğ. (2002) mikro alglerden Tetraselmis gracilis, Isochrysis galbana ve Chaetoceros calcitrans türlerinin büyüme hılarını Ulva lactuca özütü ve vitamin takviyeleri $\left(\mathrm{B}_{1}\right.$ ve $\left.\mathrm{B}_{12}\right)$ kullanarak \%250 - 325 arasında artış sağlamışlardır. Robertson-Andersson ve di ̌̆. (2006) farklı konsantrasyonlarda kullanılan Ecklonia maxima s1v1 özütünün Gracilaria gracilis' in büyüme hızını günlük \%6’ya kadar arttırdığını bildirmişlerdir.
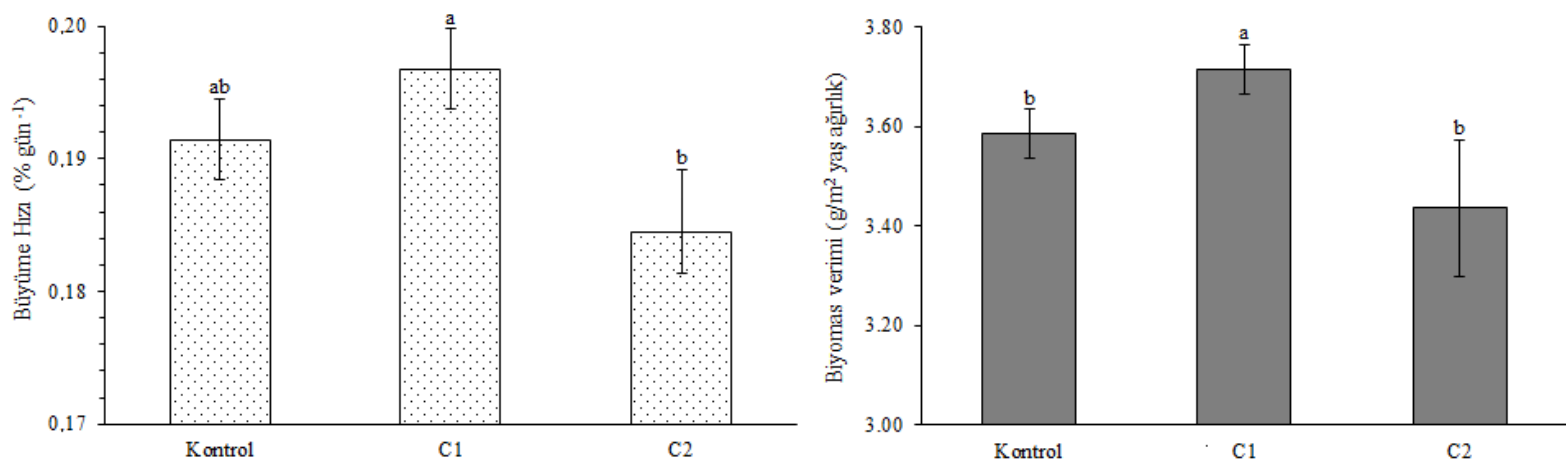

Şekil 1. Deneme gruplarının büyüme hızı ve biyomas verimlerinde meydana gelen değişimler

Yetiștiricilik denemeleri sonucunda elde edilen biyomasın besin kompozisyonlarında meydana gelen değişimler Tablo 2'de gösterilmiştir. En yüksek ham yağ içeriği $\mathrm{C}_{1}$ grubunda saptanmıştır. Kontrol grubunun ham yağ içeriği ise $\% 1,18 \pm 0,03$ olarak ölçülmüştür. Çeşitli çalışmalarda T. barbata türünün ham yă̆ içeriğinin \%1,44 ile 10,3 arasında değişim gösterdiği bildirilmiştir (Cirik ve diğ., 2010; Manev, Iliev ve Vachkova, 2013; Panayotova ve Stancheva, 2013). Çalışma sonucunda elde edilen ham yăg değerleri incelendiğinde kontrol grubu dişında diğer iki gruba ait verilerin önceki çalışmalarla benzerlik gösterdiği görülmüştür. Gómez Pinchetti, del Campo Fernández, Moreno Díez ve Reina (1998) ve Toth ve diğ. (2020) Ulva türlerinin ham yağ içerikleri ile ortamdaki azot konsantrasyonu arasında ters yönlü bir ilişki olduğunu bildirmişlerdir. Kontrol grubunun azot içeriğinin diğer deneme gruplarından daha yüksek olması nedeniyle ham yağ içeriklerinin de düşük olduğu sonucuna varılmıştır. $\mathrm{C}_{1}$ ve kontrol gruplarının protein içeriklerinin birbirine yakın olduğu saptanmıştır (Tablo 2). En düşük ham protein içeriği ise $\mathrm{C}_{2}$ grubunda bulunmuştur. Zavodnik ve Juranic (1982) alglerin ham protein içerikleri ile alglerin büyüme hızları arasında pozitif bir ilişki olduğunu bildirmişlerdir. Çalışmamızda büyüme hızı ve biyomas verimi yüksek olan $\mathrm{C}_{1}$ ve kontrol gruplarının aynı zamanda protein içeriklerinin de yüksek olduğu 
belirlenmiştir. En yüksek kül içeriği $\mathrm{C}_{2}$ grubunda belirlenmiştir (Tablo 2). Elde edilen sonuçlar aynı türün farklı ortamlar kullanarak yetiştirildiği Cirik ve diğ. (2010) tarafından gerçekleştirilen çalışma ile benzerlik göstermektedir. Deneme gruplarının su içeriklerinin birbirine yakın olduğu $(p>0,05)$ çalışma sonucunda belirlenmiştir. Schiener, Black, Stanley ve Green (2015) esmer alg talluslarının su içeriğinin \%85 civarında olduğunu bildirmiştir. Çalışmamız sonucunda elde edilen verilen önceki çalışmanın değerleri arasındadır.

Tablo 2. Deneme gruplarının besin kompozisyonlarında meydana gelen değişimler.

\begin{tabular}{lllll}
\hline & Yağ \% & Protein \% & Kül \% & Su \% \\
\hline $\mathrm{C}_{1}$ & $2,19 \pm 0,06^{\mathrm{a}}$ & $19,05 \pm 0,06^{\mathrm{a}}$ & $34,41 \pm 0,09^{\mathrm{ab}}$ & $86,07 \pm 1,52^{\mathrm{a}}$ \\
$\mathrm{C}_{2}$ & $2,00 \pm 0,04^{\mathrm{b}}$ & $16,85 \pm 0,17^{\mathrm{b}}$ & $35,29 \pm 0,24^{\mathrm{a}}$ & $86,96 \pm 0,58^{\mathrm{a}}$ \\
Kontrol & $1,18 \pm 0,03^{\mathrm{c}}$ & $18,24 \pm 0,29^{\mathrm{a}}$ & $33,48 \pm 0,37^{\mathrm{b}}$ & $85,60 \pm 1,18^{\mathrm{a}}$ \\
\hline
\end{tabular}

Deneme gruplarının yağ asidi kompozisyonlarında meydana gelen değişimler Tablo 3 'de gösterilmiştir. Tüm grupların yağ asidi içeriklerinin yarısından fazlasını doymuş yağ asitlerinin (SFA) oluşturduğu çalışma sonucunda belirlenmiş olup gruplar arasında istatistiksel olarak anlamlı farklılıkların olmadığ 1 saptanmıştır $(p>0,05)$. Doymuş yağ asitlerin arasında da palmitik asit (C16:0) miktarının yüksek olduğu gözlemlenmiştir. Aynı tür için benzer sonuçlar Caf, Şen Özdemir, Yılmaz, Durucan ve Ak (2019) tarafında da rapor edilmiştir. Deneme gruplarımızın tekli doymamış yağ asitleri (MUFA) içeriği \%23,51 10,23 ile 25,36 $\pm 0,22$ arasında değişim göstermiş (Tablo 3 ) olup grupların palmitoleik asit (C16:1) ile oleik asit (C18:1) miktarlarının yüksek olduğu belirlenmiştir. $T$. barbata türlerinin palmitik, palmitoleik asit ve oleik asit içeriklerinin diğer yağ asitlerine göre daha fazla olduğu Caf ve diğ. (2019) ve Vizetto-Duarte, Pereira, Bruno de Sousa, Pilar Rauter, Albericio, Custódio, Barreira ve Varela (2015) tarafindan da bildirilmiștir. Tüm grupların çoklu doymamış yağ asitleri (PUFA) toplamı \%20'nin üzerinde olduğu çalışma sonucunda belirlenmiş olup bu yağ asitlerin büyük çoğunluğunu Epoksieikosatrienoik asitten (20:3n3, EET) oluştuğu belirlenmiştir (Tablo 3). Araşidonik asit metabolizması sırasında oluşan sinyal mollekülleri olan EET'ler kan basıncını düşürmesi ve enflamasyon önlemesi nedenleriyle insan sağlı̆̆1 için önemlidir (Thomson, Askari ve Bishop-Bailey, 2012). Grupların Eikosapentaenoik asit (C20:5n3, EPA) içerikleri de \%3'ün üzerinde bulunmuştur. En yüksek EPA içerikleri $\mathrm{C}_{1}$ ve kontrol gruplarında olduğu görülmüştür. Diğer önemli omega 3 yağ asitlerinden olan Dokosaheksaenoik asit (C22:6n3, DHA) ise en yüksek $\mathrm{C}_{1}$ grubundan elde edilmiştir (Tablo 3). Makro algler ARA (C20:4n6) ve EPA içerikleri yüksek olmasına karşın DHA içerikleri düşüktür (Dawczynski, Schubert ve Jahreis, 2007). Li Fan, Han ve Lou (2002) esmer alglerin DHA içeriklerinin çok düşük olduğu veya olmadığını bildirmiştir. En yüksek PUFA içeriği büyüme hızının en yüksek olduğu $\mathrm{C}_{1}$ grubunda saptanmıştır. T. barbata türlerinin PUFA içeriklerin \%19,79 ile 29,06 arasında değişim gösterdiği çeşitli çalışmalarda bildirilmiştir (Künili ve Ak, 2020; Vizetto-Duarte ve diğ., 2015). Alglerin biyokimyasal kompozisyonları 1şı, sıcaklık, tuzluluk ve $\mathrm{pH}$ gibi abiyotik faktörlerin etki etmesi nedeniyle (Alishah Aratboni, Rafiei, Garcia-Granados, Alemzadeh ve Morones-Ramírez, 2019; Chen ve Durbin, 1994; Cirik ve diğ., 2010; Toth ve diğ., 2020) sonuçların önceki çalışmalara göre farklı olduğu düşünülmektedir. $n 6: n 3$ oran1 farklı türlerin yağ içeriklerini karşılaştırmak için kullanışıı bir gösterge olarak kabul edilmektedir. Dünya sağlık örgütü (DSÖ) kalp ve damar sağlığı için n6:n3 oranının 10'dan düşük olmasını önermektedir (Kumari, Bijo, Mantri, Reddy ve Jha, 2013). Çalışmamızda elde edilen sonuçlar incelendiğinde deneme gruplarının n6:n3 oranlarının DSÖ'nün önerdiği değer aralığı içerisinde olduğu görülmüştür. Dawczynski ve diğ. (2007) ve López-López, Cofrades ve Jiménez-Colmenero (2009) makro alglerin sağlıklı yiyecekler grubunda tüketilmesini önermişlerdir. 
Tablo 3. Deneme gruplarının \% yağ asitlerinde meydana gelen değişimler

\begin{tabular}{|c|c|c|c|}
\hline Yağ Asitleri & $\mathrm{C}_{1}$ & $\overline{C_{2}}$ & Kontrol \\
\hline C13:0 & $0,47 \pm 0,09^{a}$ & $0,28 \pm 0,15^{\mathrm{a}}$ & $0,16 \pm 0,10^{\mathrm{a}}$ \\
\hline C14:0 & $5,23 \pm 0,44^{\mathrm{ab}}$ & $6,72 \pm 0,43^{\mathrm{a}}$ & $4,79 \pm 0,38^{b}$ \\
\hline C15:0 & $0,42 \pm 0,08^{\mathrm{a}}$ & $0,54 \pm 0,11^{\mathrm{a}}$ & $0,41 \pm 0,06^{\mathrm{a}}$ \\
\hline C16:0 & $29.63 \pm 0,29^{b}$ & $30.28 \pm 0,36^{\mathrm{b}}$ & $32.64 \pm 0,09^{a}$ \\
\hline $\mathrm{C} 17: 0$ & $5,43 \pm 0,30^{\mathrm{a}}$ & $5,30 \pm 0,47^{\mathrm{a}}$ & $6,34 \pm 0,49^{a}$ \\
\hline C18:0 & $1,84 \pm 0,05^{\mathrm{a}}$ & $1,72 \pm 0,02^{\mathrm{a}}$ & $1,95 \pm 0,25^{\mathrm{a}}$ \\
\hline C20:0 & $0,97 \pm 0,10^{\mathrm{a}}$ & $0,26 \pm 0,12^{b}$ & $0,19 \pm 0,02^{\mathrm{b}}$ \\
\hline $\mathrm{C} 21: 0$ & $11,78 \pm 0,26^{\mathrm{a}}$ & $12,63 \pm 0,33^{\mathrm{a}}$ & $10,40 \pm 0,03^{b}$ \\
\hline $\mathrm{C} 22: 0$ & $0,00 \pm 0,00^{b}$ & $0,00 \pm 0,00^{\mathrm{b}}$ & $0,16 \pm 0,03^{\mathrm{a}}$ \\
\hline C23:0 & $0,22 \pm 0,01^{\mathrm{a}}$ & $0,06 \pm 0,09^{\mathrm{a}}$ & $0,14 \pm 0,00^{\mathrm{a}}$ \\
\hline$\Sigma$ SFA & $56,12 \pm 0,81^{a}$ & $57,78 \pm 0,02^{a}$ & $57,20 \pm 0,24^{a}$ \\
\hline C14:1 & $0,00 \pm 0,00^{\mathrm{a}}$ & $0,00 \pm 0,00^{\mathrm{a}}$ & $0,16 \pm 0,08^{\mathrm{a}}$ \\
\hline C15:1 & $1,50 \pm 0,52^{\mathrm{a}}$ & $1,19 \pm 0,31^{\mathrm{a}}$ & $1,45 \pm 0,25^{\mathrm{a}}$ \\
\hline C16:1 & $4,09 \pm 0,02^{a b}$ & $4,14 \pm 0,08^{\mathrm{a}}$ & $3,90 \pm 0,04^{\mathrm{b}}$ \\
\hline C17:1 & $0,20 \pm 0,13^{\mathrm{a}}$ & $0,14 \pm 0,03^{\mathrm{a}}$ & $0,34 \pm 0,02^{\mathrm{a}}$ \\
\hline $\mathrm{C} 18: 1 n 9 C+9 T$ & $17,55 \pm 0,05^{\mathrm{b}}$ & $19.19 \pm 0,26^{\mathrm{a}}$ & $17.26 \pm 0,05^{b}$ \\
\hline $\mathrm{C} 20: \ln 9$ & $0,80 \pm 0,21^{\mathrm{a}}$ & $0,63 \pm 0,75^{\mathrm{a}}$ & $0,26 \pm 0,03^{\mathrm{a}}$ \\
\hline $\mathrm{C} 22: 1 n 9$ & $0,09 \pm 0,13^{\mathrm{a}}$ & $0,07 \pm 0,11^{\mathrm{a}}$ & $0,14 \pm 0,01^{\mathrm{a}}$ \\
\hline इMUFA & $24,22 \pm 0,66^{a b}$ & $25,36 \pm 0,22^{a}$ & $23,51 \pm 0,23^{b}$ \\
\hline $\mathrm{C} 18: 3 n 3$ & $1.69 \pm 0,07^{b}$ & $1.47 \pm 0,04^{\mathrm{c}}$ & $1.93 \pm 0,01^{\mathrm{a}}$ \\
\hline C20:2 & $0,56 \pm 0,01^{\mathrm{a}}$ & $0,57 \pm 0,02^{\mathrm{a}}$ & $0,53 \pm 0,00^{\mathrm{a}}$ \\
\hline $\mathrm{C} 20: 3 n 3$ & $11,78 \pm 0,25^{\mathrm{a}}$ & $12,63 \pm 0,33^{a}$ & $10,50 \pm 0,11^{b}$ \\
\hline $\mathrm{C} 20: 3 n 6$ & $0,89 \pm 0,01^{\mathrm{a}}$ & $0,89 \pm 0,04^{\mathrm{a}}$ & $0,96 \pm 0,00^{\mathrm{a}}$ \\
\hline $\mathrm{C} 20: 4 n 6$ & $0,43 \pm 0,10^{a b}$ & $0,49 \pm 0,00^{\mathrm{a}}$ & $0,32 \pm 0,01^{b}$ \\
\hline $\mathrm{C} 20: 5 n 3$ & $4,80 \pm 0,09^{\mathrm{a}}$ & $3,55 \pm 0,03^{\mathrm{b}}$ & $4,63 \pm 0,03^{\mathrm{a}}$ \\
\hline $\mathrm{C} 22: 2$ & $0,73 \pm 0,55^{\mathrm{a}}$ & $0,55 \pm 0,05^{\mathrm{a}}$ & $0,25 \pm 0,03^{a}$ \\
\hline $\mathrm{C} 22: 6 n 3$ & $1,27 \pm 0,02^{\mathrm{a}}$ & $0,96 \pm 0,02^{b}$ & $0,80 \pm 0,00^{b}$ \\
\hline इPUFA & $22,15 \pm 0,19^{\mathrm{a}}$ & $21,08 \pm 0,40^{a b}$ & $20,15 \pm 0,44^{b}$ \\
\hline$n 6$ & $1,31 \pm 0,07^{a}$ & $1,37 \pm 0,05^{\mathrm{a}}$ & $1,28 \pm 0,01^{a}$ \\
\hline$n 3$ & $7,76 \pm 0,05^{\mathrm{a}}$ & $5,98 \pm 0,02^{\mathrm{c}}$ & $7,33 \pm 0,07^{\mathrm{b}}$ \\
\hline$n 6 / n 3$ & $0,17 \pm 0,01^{b}$ & $0,23 \pm 0,01^{\mathrm{a}}$ & $0,17 \pm 0,00^{b}$ \\
\hline
\end{tabular}

\section{Sonuç}

$\mathrm{Bu}$ çalışmada önemli bir aljinat kaynağı olan $T$. barbata yetiştiriciliğinde özellikle Şubat - Temmuz ayları arasında Çanakkale sahil şeridinde yı̆̆ınlara neden olan $C$. sinuosa'nın sıvı özütünün kullanımı araştırılmıştır. Ekonomik kaynaklarımızın üretimi amacıyla deniz kıyısında birikerek ekolojik sorunlara neden olan başka canlıların kullanılması hem ekonomik hem de ekolojik yönden önem taşımaktadır. Çalışma sonucunda $T$. barbata yetiştiriciliğinde $C$. sinuosa siv1 özütlerinin besin tuzu olarak kullanılabileceği saptanmıştır. $\mathrm{Bu}$ bağlamda elde edilen sonuçların Treptacantha türlerinin yetiştiriciliği 
ve değerlendirilmesi üzerine çalışmalar yürüten araştırmacılara ve girişimcilere faydalı olacağı düşünülmektedir.

\section{Teşekkür}

Bu çalışma, ÇOMU BAP tarafından FYL-2014-294 numaralı proje kapsamında desteklenmiştir. Çalışma, İlknur AK'ın danışmanlığında yürütülen ve Merve KÜNILİ tarafından hazırlanan "Makro alglerden elde edilen gübrelerin Cystoseira barbata (Phaeophyceae) yetiştiriciliğinde kullanılması" başlıklı yüksek lisans tezi kapsamında gerçekleştirilmiştir.

\section{Kaynaklar}

Abdel-Kareem, M. S., Mohy El.Din, S. M., \& Ibrahim, E.-S. M. (2020). Optimization of Growth Conditions and Biochemical Composition of Microchloropsis salina, Cultured with Three Macroalgal Aqueous Extracts. Thalassas: An International Journal of Marine Sciences, 36, 415429. doi: 10.1007/s41208-020-00218-8

Ajansı, A. (2018). İzmir Körfezi'nde şaşırtan görüntü. NTV. Erişim tarihi: 29.10, 2020, adres: https://www.ntv.com.tr/galeri/turkiye/izmirkorfezinde-sasirtan-goruntu, TyDExybnFUSXxV_RepQa2Q/2e3SfQO8hEGQ _u4Cez8Mjw

Ajansı, D. H. (2020). İzmir'de korkutan görüntü! Sahil 'deniz marulu' doldu! Erişim tarihi: 29.10, 2020, adres: https://www.denizhaber.net/izmirdekorkutan-goruntu-sahil-deniz-marulu-dolduhaber-97981.htm

Ak, İ. (2015). Sucul ortamın ekonomik bitkileri; makro algler. Dünya Gıda Dergisi, Aralık 2015, 88-97.

Ak, İ., Çetin, Z., Cirik, Ş., \& Göksan, T. (2011). Gracilaria verrucosa (Hudson) Papenfuss culture using an agricultural organic fertilizer. Fresenius Environmental Bulletin, 20(8a), 2156-2162.

Ak, İ., Öztaşkent, C., Özüdoğru, Y., \& Göksan, T. (2015). Effect of sodium acetate and sodium nitrate on biochemical composition of green algae Ulva rigida. Aquaculture International, 23(1), 1-11. doi: 10.1007/s10499-014-9793-3

Ak, İ., \& Türker, G. (2018). Antioxidant properties and phytochemicals of three brown macro algae from the Dardanelles (Çanakkale) strait. Agricultural Science and Technology, 10(4), 354357. doi: 10.15547/ast.2018.04.065

Alishah Aratboni, H., Rafiei, N., Garcia-Granados, R., Alemzadeh, A., \& Morones-Ramírez, J. R. (2019). Biomass and lipid induction strategies in microalgae for biofuel production and other applications. Microbial Cell Factories, 18(1), 178. doi: 10.1186/s12934-019-1228-4
AOAC (2000). Official methods of analysis of AOAC (Association of Official Analytical Chemists) International (17th ed.) (pp. 1298): AOAC International,Gaithersburg, MD.

Baghdadli, D., Tremblin, G., \& Ducher, M. (1994). The Effects of Light Quality on Growth, Photosynthesis and Development in Cultivated Thalli of Cystoseira barbata C. Ag. f. aurantia (Kütz.) Giaccone (Phaeophyceae, Fucales). 37(1), 43. doi:10.1515/botm.1994.37.1.43

Bastos, G. F. P. C. (2019). Cultivation of the wild seaweed Gracilaria gracilis under laboratory scale: The Effect of Light Intensity and Nutrients on Growth, Pigment and Total Soluble Protein Content. (Master's Degree), Politécnico de Leiria, Peniche, Portugal.

Bollen, M., Pilditch, C. A., Battershill, C. N., \& Bischof, K. (2016). Salinity and temperature tolerance of the invasive alga Undaria pinnatifida and native New Zealand kelps: Implications for competition. Marine Biology, 163(9), 194. doi: 10.1007/s00227-016-2954-3

Borges, D., Araujo, R., Azevedo, I., \& Pinto, I. S. (2020). Sustainable management of economically valuable seaweed stocks at the limits of their range of distribution: Ascophyllum nodosum (Phaeophyceae) and its southernmost population in Europe. Journal of Applied Phycology, 32(2), 1365-1375. doi: 10.1007/s10811-019-02002-5

Caf, F., Şen Özdemir, N., Yılmaz, Ö., Durucan, F., \& Ak, İ. (2019). Fatty acid and lipophilic vitamin composition of seaweeds from Antalya and Çanakkale (Turkey). Grasas Y Aceites(3), 1-7. doi: 10.3989/gya.0704182

Casas-Beltrán, D. A., Gallaher, C. M., Hernandez Yac, E., Febles Moreno, K., Voglesonger, K., LealBautista, R. M., \& Lenczewski, M. (2020). Seaweed Invasion! Temporal Changes in Beach Conditions Lead to Increasing Cenote Usage and Contamination in the Riviera Maya. Sustainability, 12(6), 2474.

Chen, C. Y., \& Durbin, E. G. (1994). Effects of pH on the growth and carbon uptake of marine phytoplankton. Marine Ecology Progress Series, 109(1), 83-94.

Cirik, Ş., Şen, E., \& Ak, İ. (2010). Brown algae Cystoseira barbata (Stackhouse) C. Agardh culture and changes in it chemical composition. Journal of fisheriessciences.com, 4(4), 354-361. doi: 10.3153/jfscom.2010038

Dawczynski, C., Schubert, R., \& Jahreis, G. (2007). Amino acids, fatty acids, and dietary fibre in edible seaweed products. Food Chemistry, 103(3), 891899. doi:10.1016/j.foodchem.2006.09.041 
Engin, Y. O., Yağmur, B., Cirik, S., Okur, B., Eşiyok, D., \& Gökpınar, Ş. (2019). Ulva rigida (C. Agardh) Makroalginin Fasulye Bitkisinin Üretiminde Organik Madde Kaynağı Olarak Kullanımının Araştırılması. Acta Aquatica Turcica, 15(2), 151-162. doi: 10.22392/actaquatr.577506

Eşiyok, D., \& Bozokalfa, M. K. (2007). Fasulye yetiştiriciliği. Dünya Yayıncılık, Gıda Dergisi, 6, 88-90.

FAO (2020). The State of World Fisheries and Aquaculture 2020. Sustainability in action (pp. 224). Rome: FAO Fisheries and Aquaculture Department.

Floreto, E. A. T., Hirata, H., Ando, S., \& Yamasaki, S. (1993). Effects of Temperature, Light Intensity, Salinity and Source of Nitrogen on the Growth, Total Lipid and Fatty Acid Composition of Ulva pertusa Kjellman (Chlorophyta). Botanica Marina,36(2), 149. doi:10.1515/botm.1993.36.2.149

Folch, J., Lees, M., \& Sloane Stanley, G. H. (1957). A simple method for the isolation and purification of total lipides from animal tissues. $\mathrm{J}$ Biol Chem, 226(1), 497-509.

Gómez Pinchetti, J. L., del Campo Fernández, E., Moreno Díez, P., \& Reina, G. G. (1998). Nitrogen availability influences the biochemical composition and photosynthesis of tank-cultivated Ulva rigida (Chlorophyta). Journal of Applied Phycology, 10(4),383. doi:10.1023/a:1008008912991

Gong, J., Liu, Z., \& Zou, D. (2020). Growth and photosynthetic characteristics of Gracilaria lemaneiformis (Rhodophyta) and Ulva lactuca (Chlorophyta) cultured under fluorescent light and different LED light. Journal of Applied Phycology, 32, 3265-3272. doi: 10.1007/s10811-020-02151-y

Jones, A. G., Quillien, N., Fabvre, A., Grall, J., Schaal, G., \& Le Bris, H. (2020). Green macroalgae blooms (Ulva spp.) influence trophic ecology of juvenile flatfish differently in sandy beach nurseries. Marine Environmental Research, 154, 104843.

doi: https://doi.org/10.1016/j.marenvres.2019.104843

Kaladharan, P., Gireesh, R., \& Smitha, K. S. (2002). Cost effective medium for the laboratory culture of live feed micro algae. Seaweed Research and Utilisation, 24(1), 35-40.

Kumari, P., Bijo, A. J., Mantri, V. A., Reddy, C. R., \& Jha, B. (2013). Fatty acid profiling of tropical marine macroalgae: an analysis from chemotaxonomic and nutritional perspectives. Phytochemistry, 86, 44-56.
Künili, M., \& Ak, İ. (2020). Ulva rigida (Ulvophyceae) sıv1 özütünün Treptacantha barbata (Phaeophyceae) yetiștiriciliğinde algin büyümesi ve biyokimyasal içeriği üzerine etkisi. EJONS International Journal on Mathematic, Engineering and Natural Sciences, 15(September), 687-698. doi:10.38063/ejons.314

Li, X., Fan, X., Han, L., \& Lou, Q. (2002). Fatty acids of some algae from the Bohai Sea. Phytochemistry, 59(2),157-161.doi:10.1016/S00319422(01)00437-X

López-López, I., Cofrades, S., \& Jiménez-Colmenero, F. (2009). Low-fat frankfurters enriched with n-3 PUFA and edible seaweed: Effects of olive oil and chilled storage on physicochemical, sensory and microbial characteristics. Meat Sci, 83(1), 148154.

Loureiro, R. R., Reis, R. P., \& Critchley, A. T. (2010). In vitro cultivation of three Kappaphycus alvarezii (Rhodophyta, Areschougiaceae) variants (green, red and brown) exposed to a commercial extract of the brown alga Ascophyllum nodosum (Fucaceae, Ochrophyta). Journal of Applied Phycology, 22(1), 101-104. doi: 10.1007/s10811-009-9412-2

Manev, Z., Iliev, A., \& Vachkova, V. (2013). Chemical characterization of brown seaweed Cystoseira barbata. Bulgarian Journal of Agricultural Science, 19, 12-15.

NMKL (2007). Nordisk Metodikkomité for Næringsmidler-NMKL. Nordic Committee on Food Analysis: method no. 186. Lyngby, Danmark.

Özdamar, K. (1997). Paket programlar ile istatistiksel veri analizi I. Eskişehir: Kaan Yayın evi.

Pacheco-Ruíz, I., Zertuche-González, J. A., ArroyoOrtega, E., \& Valenzuela-Espinoza, E. (2004). Agricultural fertilizers as alternative culture media for biomass production of Chondracanthus squarrulosus (Rhodophyta, Gigartinales) under semi-controlled conditions. Aquaculture, 240(1), 201-209. doi:10.1016/j.aquaculture.2004.05.044

Panayotova, V., \& Stancheva, M. (2013). Fat soluble vitamins and fatty acids composition of Black Sea Cystoseira barbata. Paper presented at the CBU International conference on integration and innovation in science and education, Prague, Czech Republic.

Raoof, B., Kaushik, B. D., \& Prasanna, R. (2006). Formulation of a low-cost medium for mass production of Spirulina. Biomass and Bioenergy, 30(6),537-542. doi:10.1016/j.biombioe.2005.09.006 
Robertson-Andersson, D. V., Leitao, D., Bolton, J. J., Anderson, R. J., Njobeni, A., \& Ruck, K. (2006). Can kelp extract (KELPAK $®)$ be useful in seaweed mariculture? Journal of Applied Phycology, 18, 315-321. doi: 10.1007/978-1-40205670-3_12

Schiener, P., Black, K., Stanley, M., \& Green, D. (2015). The seasonal variation in the chemical composition of the kelp species Laminaria digitata, Laminaria hyperborea, Saccharina latissima and Alaria esculenta. Journal Applied Phycology, 27(1), 363-373. doi: 10.1007/s10811014-0327-1

Sivasankari, S., Venkatesalu, V., Anantharaj, M., \& Chandrasekaran, M. (2006). Effect of seaweed extracts on the growth and biochemical constituents of Vigna sinensis. Bioresource Technology, 97(14), 1745-1751. doi:10.1016/j.biortech.2005.06.016

Smith, F. A., \& Walker, N. A. (1980). Photosynthesis by aquatic plants: effects of unstirred layers in relation to assimilation of $\mathrm{CO}_{2}$ and $\mathrm{HCO}_{3}{ }^{-}$and to carbon isotopic discrimination. New Phytologist, 86(3), 245-259. doi: $10.1111 / \mathrm{j} .1469$ 8137.1980.tb00785.x

Tompkins, J., Deville, M. M., Day, J. G., \& Turner, M. F. (1995). Catalogue of strains. Culture Collection of Algae and Protozoa, Ambleside, UK.

Thomson, S. J., Askari, A., \& Bishop-Bailey, D. (2012). Anti-inflammatory effects of epoxyeicosatrienoic acids. International journal of vascular medicine, 2012, 605101-605101. doi: $10.1155 / 2012 / 605101$

Toth, G. B., Harrysson, H., Wahlström, N., Olsson, J., Oerbekke, A., Steinhagen, S., Kinnby, A., White, J., Albers, E., Edlund, U., Undeland, I., Pavia, H. (2020). Effects of irradiance, temperature, nutrients, and $\mathrm{pCO}_{2}$ on the growth and biochemical composition of cultivated Ulva fenestrata. Journal of Applied Phycology, 32, 3243-3245. doi: 10.1007/s10811-020-02155-8

Troell, M., Halling, C., Nilsson, A., Buschmann, A. H., Kautsky, N., \& Kautsky, L. (1997). Integrated marine cultivation of Gracilaria chilensis (Gracilariales, Rhodophyta) and salmon cages for reduced environmental impact and increased economic output. Aquaculture, 156(1), 45-61. doi:10.1016/S0044-8486(97)00080-X

Turan, M., \& Köse, C. (2004). Seaweed extracts improve copper uptake of grapevine. Acta Agriculturae Scandinavica, Section B-Soil \& Plant Science, 54(4), 213-220. doi: 10.1080/09064710410030311
UIPAC (1979). Standards methods for the analysis of oils, fats ad derivatives: Pergamon Press, Oxford.

Vizetto-Duarte, C., Pereira, H., Bruno de Sousa, C., Pilar Rauter, A., Albericio, F., Custódio, L., Barreira, L., \& Varela, J. (2015). Fatty acid profile of different species of algae of the Cystoseira genus: a nutraceutical perspective. Natural Product Research, 29(13), 1264-1270. doi: 10.1080/14786419.2014.992343

Werlinger, C., Mansilla, A., Villarroel, A., \& Palacios, M. (2009). Effects of photon flux density and agricultural fertilizers on the development of Sarcothalia crispata tetraspores (Rhodophyta, Gigartinales) from the Strait of Magellan, Chile. In M. A. Borowitzka, A. T. Critchley, S. Kraan, A. Peters, K. Sjøtun \& M. Notoya (Eds.), Nineteenth International Seaweed Symposium: Proceedings of the 19th International Seaweed Symposium, held in Kobe, Japan, 26-31 March, 2007. (pp. 307315). Dordrecht: Springer Netherlands.

Zavodnik, N., \& Juranic, L. J. (1982). Content of Phosphorus and Protein in Seaweeds from the Area of Fazana (Nort Adriatic Sea). Acta Adriatica, 23, 271-279. 